\title{
Designing representations of trigonometry instruction to study the rationality of community college teaching
}

\author{
Vilma Mesa - Patricio Herbst \\ University of Michigan \\ Corresponding Author: \\ Vilma Mesa \\ 3111 SEB School of Education \\ 610 East University Ann Arbor, MI 48109-1259 \\ e-mail: vmesa@umich.edu \\ phone: 7346470628
}

Abstract

We describe the process followed to design representations of mathematics teaching in a community college. The end product sought are animated videos to be used in investigating the practical rationality that community college instructors use to justify norms of the didactical contract or possible departures from those norms. We have chosen to work within the trigonometry course, in the context of an instructional situation, "finding the values of trigonometric functions," and specifically on a case of this situation that occurs as instructors and students are working on examples on the board. We describe the design of the material needed to produce the animations: (1) identifying an instructional situation, (2) identifying norms of the contract that are key in that situation, (3) selecting or creating a scenario that illustrates those norms, (4) proposing alternative scenarios that instantiate breaches of those norms, and (5) anticipating justifications or rebuttals for the breaches that could be found in instructors' reactions. We illustrate the interplay of contextual and theoretical elements as we make decisions and state hypothesis about the situation that will be prototyped.

Keywords: Representation of teaching, community colleges, trigonometry, didactical contract, classroom interaction, teacher thinking, teaching practice 


\section{Introduction}

Herbst and Chazan (2003a) argued that video representations of teaching can be seen not only as cases of practice but also as probes on the rationality that practitioners use in practice, in the same way that Rorschach blots can be probes on the thinking of a patient. Since that publication, and in the context of the Thought Experiments in Mathematics Teaching [ThEMaT] project, they have developed a new kind of representation of teaching - animations of classroom scenarios, deliberately designed to probe some of the unspoken norms of classroom practice (Herbst and Chazan, 2003b). Herbst and Miyakawa (2008) provided some details of how those animations are produced to be prototypes of models of instructional situations: Instructional situations are identified and then modeled by hypothesizing the norms or tacit responsibilities of classroom participants in a situation; scenarios are then created that fulfill some of those norms but breach others; finally those scenarios are prototyped in a cartoon animation. Herbst, Nachlieli and Chazan (in press) have shown how such animations can elicit data that informs about the rationality of teaching.

This paper describes how we applied those ideas in an instrument design process that could be conceived as a case of design research (Kelly 2004). Usual applications of design research in mathematics education (e.g., Cobb 2000) start from making hypotheses about students' ways of knowing and engage in creating materials (curriculum or technology) that are hypothesized to be capable of bringing those ways of knowing to the surface where they can be probed. The research process feeds from the initial use of those materials, tailoring the revisions of those materials to achieve the ends that those materials are being designed for (Cobb, Confrey, diSessa, Lehrer and Schauble 2003). This knowledge is then used to re-engineer the materials and the process starts again. Rather than designing curriculum or a learning technology we 
design a research instrument; because this instrument is used as part of a technique to elicit something teachers are hypothesized to have (practical rationality) and because we know from prior research the form this rationality takes when elicited (modally qualified, occasionally justified stories that present and ponder alternatives to a given scenario; see Herbst et al. in press), it seems reasonable to implement a research and development process similar to that used to design educational materials. In this paper, we present the first step of this process; we illustrate the steps involved in designing a research tool—animations of classroom interaction in trigonometry classes at a community college — to test hypotheses about the norms that regulate the didactical contract of these classrooms. We use a corpus of trigonometry lessons from a community college in the Midwest of the United States to hypothesize the instructors' rationality behind the norms of the didactical contract that governs the interactions between instructors and students while solving examples on the board. We anticipate events that might breach those norms were they to happen in a classroom, and then use such breaching events as the bare bones of three stories that we later represent using an animation of cartoon characters.

\section{Context: Trigonometry at Community Colleges}

The animations are meant to be representations of trigonometry teaching that occurs in a typical U. S. community college. Community colleges are tertiary institutions that offer the first two years of a college education; such coursework might be sufficient to ensure a paraprofessional job or to transfer to a four-year institution where students can finish a college degree. In addition, the community colleges offer certification in vocational and technical areas, continuous education and enrichment courses. In recent years, these institutions have assumed the major responsibility for offering remediation courses for students who intend to start a college degree 
(Bailey and Morest 2006); the courses also give credit for adults who want to obtain a highschool diploma.

Community colleges are an important site for probing the process of representing instruction. Similar to K-12 schools but different from other higher-education institutions, community colleges have an open access policy for admissions; a content-specific placement exam determines in which classes students should enroll. For this reason, any given class can have a wide variation in student characteristics in terms of their academic background (from unfinished high school to an advanced degree in a different field), goals (vocational or technical certificate, transfer, enrichment), present occupation (e.g., blue collar, clerical, management, unemployed), age, socioeconomic status, race and ethnicity, physical ability, and type (full/part time) and duration of enrollment. Unlike K-12 schools, attendance is not mandatory and students pay tuition, but because of substantial support from the community, state and Federal government (around 70\%), the cost per credit is relatively low compared to private, for-profit, or other four-year institutions. To sustain operations, community colleges seek to keep low operating costs, which, in combination with enrollment uncertainty translate to a ratio of about 4 to 1 part-time to full-time instructors and results in wide variation of instructor preparation, commitment, goals, and teaching approaches (Keim and Biletzky 1999; Schuetz 2002). Students who do not achieve the passing grade for the course must repeat it until they attain a satisfactory grade. By the time students take the trigonometry course, they might have completed between one and three mathematics courses at the college.

Trigonometry is one of the mathematical domains conventionally taught in community colleges, either as a separate course or incorporated into other courses that are prerequisites to calculus (Lutzer, Maxwell and Rodi 2007). The course can be perceived as a skills- and 
knowledge-building course, in which the purpose is to ensure that students demonstrate competence in solving standard problems of trigonometry and familiarity with the definition and properties of the trigonometric functions. In the college where we collected the intact classroom data, the course has a guiding textbook (Barnett, Ziegler and Byleen 2006) and a master syllabus that outlines the knowledge for which students and instructors are held accountable.

\section{Theoretical and Methodological Underpinnings}

We define now theoretical and methodological constructs that are key for the design process: the didactical contract, the instructional situation, and the breaching experiments.

\subsection{The Didactical Contract}

Our observations of trigonometry classes suggest that there are default norms ${ }^{1}$ for how teacher and students relate to each other and in relationship to the knowledge at stake; these norms articulate a didactical contract for this course: Like any didactical contract, the contract states that the teacher needs to teach the knowledge at stake to the students and the students need to learn it from the teacher (Brousseau and Otte 1991). The particular way the contract is executed in a given class could be modeled in terms of specific norms: tacit regulations that appear to underpin how teacher and students interact about content. One such norm, that we have observed enacted recurrently in trigonometry classes is that it is the prerogative and the duty of the instructor to say that students have learned a specific item of knowledge but that to make such attestation the teacher needs to rely on some evidence on the part of students (e.g., the completion of some task). The need for this exchange to happen between specific kinds of work

${ }^{1}$ Defaults, or behaviors that if present would go without saying. Alternatively, "norm" denotes tacit obligations of the teacher and the student regarding the exchange they are enacting (Herbst 2006; Herbst and Chazan 2003; Herbst and Miyakawa 2008; Herbst et al. in press). 
on the part of students and an attestation on the part of the teacher is a key norm of the contract (and a norm that is present in most contracts). Another norm, possibly derived from the former, is that the teacher needs to give students opportunities to learn to do tasks similar to those in which their learning of the knowledge at stake will be attested. This takes us to the core of what we want to understand in trigonometry classes and to the design of the instrument with which we will do that. When instructors present examples to students, they are creating opportunities for students to learn to do similar tasks and by involving students in the solution of the example instructors can attest that their students are indeed learning what they are teaching. Thus, the core question that we want to answer with the tool that we are designing is, How much and what kinds of student participation do instructors perceive as feasible to handle when they work through examples at the board?

Calls for reform in mathematics instruction at the two-year college level (Blair 2006) emphasize the importance of student participation in instructional processes, and in particular, of engaging students in classroom talk, because such engagement can make possible that students learn from their peers and that the teacher tailor subsequent instruction. Understanding the rationality with which community college instructors relate to instruction that creates more opportunity for students' participation in an instructional situation (when this is not the norm) can inform policies and curriculum that seek to improve instructional practices.

\subsection{The Instructional Situation}

In order to proceed with the design of the animations the design process requires identifying an instructional situation that would frame the classroom interaction to be prototyped. An instructional situation can be described as a set of norms that regulate the work of the teacher and 
the learners over a specific object of knowledge; a situation activates specific normative ways in which tasks are presented and how the work over time on those tasks is divided between the teacher and the students (Herbst 2006). The situation further elaborates the norms of the contract for the specifics of the knowledge at stake.

To say that a situation frames an exchange between the specific work on a specific task and the knowledge goals specified in the contract means that rather than having to engage anew in negotiating how the contract applies to the task at hand, students and teacher act as if they knew what they have to do. The usually tacit knowledge of what they have to do and when is what we refer to as the instructional situation. In the case at hand, we locate in the identified situation our investigation of the norms of the didactical contract, based on the expectation that even if those norms apply across several items of knowledge at stake, they will be realized within the particulars of an instructional exchange.

\subsection{Breaching Experiments}

The goal of our design process is to produce a representation of teaching, specifically a classroom story prototyped as an animation of cartoon characters that shows an instance of the instructional situation "finding the values of trigonometric functions." To be able to use one such representation to elicit elements of the rationality that practitioners use to sustain such instructional situation we implement a methodological hypothesis derived from the ethnomethodological notion of breaching experiment (Garfinkel and Sacks 1970). The methodological hypothesis says that a representation of teaching that reproduces most of the norms of an instructional situation but that breaches one of those norms can elicit practitioner's behaviors in which they are likely to accept that the episode represents the instructional situation 
of interest and also repair (notice, recommend modify, etc.) the tasks of teaching or studenting whose norms have been breached in the episode.

In representing the give and take of interaction and eliciting practitioners' comment on such interaction, one such story will allow investigations of how instructors manage the relationship between the contract that is established in the trigonometry class and the mathematical task a teacher and her students are occupied with. To design one such representation of teaching it is therefore important to make hypotheses about the norms that constitute the situation of interest to then choose which norms to uphold and which ones to breach.

Herbst and Miyakawa (2008) noted that norms that regulate an instructional situation concern the exchange (what work is being done and what that work trades for), the division of labor (who has to do what), and the organization of time (in what order things need to be done, how long they take, etc.). As Herbst, Chen, Weiss and González (2009) have noted, the same instructional situation can regulate interactions in different activity types. For the case of finding the values of trigonometric functions, one of those activity types is that of the teacher showing an example on the board, another could be described as having students do individual seatwork problems. While activity types describe behavioral configurations of the class work, instructional situations describe the economy of knowledge achieved through class work. We target more general norms of the didactical contract, which are usually present in a particular activity type (doing examples at the board) that could be used in several situations; we choose one of those situations (finding the values of trigonometric functions) in order to apply the design process.

We hypothesize that the norms that constitute the didactical contract and its instructional situations are sustained or justified by a practical rationality composed of dispositions to attend to a number of obligations: disciplinary, individual, interpersonal, and institutional (Herbst 
2010). As we model the situation of determining the value of trigonometric functions with a view on creating animated prototypes, we consider not only the need for norms of exchange, division of labor, and organization of time, but also whether and how community college mathematics instructors could repair breaches of those norms on account of dispositions to fulfill one or more of those obligations.

\section{Seven Stages in the Design Process}

From earlier reports on how animated representations of teaching are constructed we have identified seven stages in the design process: (1) identifying an instructional situation, (2) identifying key norms of the situation, (3) selecting or creating a scenario that illustrates the current norms, (4) proposing alternative scenarios that instantiate breaches to those norms, (5) anticipating justifications or rejections for the breaches to be found in for instructors' reactions

(6) producing the prototype, and (7) testing the prototype. Next, we describe in detail the work we have done regarding the first five stages.

We base the design work on a corpus that consists of audio recordings and field notes of 39 trigonometry lessons taught by seven instructors (including five employed part-time) at a large Midwestern suburban community college in the United States. We have interviews in which these faculty members describe their views of teaching in the college and their approaches to teaching mathematics, and their students' responses to an anonymous survey of achievement orientation goals (Mesa 2010a; Midgley, Maehr, Hruda, Anderman and Others 2000). Every instructor was observed at least three times teaching each course. From these observations we have the audio-recording of the lesson, data about who participates in the classes and how frequent that participation is, and syllabi for the courses, the examinations given in the observed 
classes, homework assignments, and the textbooks used. We do not have data showing students' independent work.

\subsection{Identifying the Instructional Situation}

The first stage in the design process consists of identifying the instructional situation that will be modeled. This choice is shaped by at least three considerations: the activity types and tasks that were observed in the trigonometry lessons, the knowledge at stake, and the anticipated final use of the animations.

\subsubsection{Activity Types and Tasks}

The teaching observed in this particular college had both commonalities across instructors and differences that appeared idiosyncratic to each of them. All instructors devoted some portion of their instructional time to present content to the students. The degree of student participation during content presentation varied depending on the type of course; compared to remedial courses, students in trigonometry classes asked or answered fewer questions (Mesa accepted). Other activities such as working with other students or solving open ended problems were infrequent: only two of the seven instructors teaching trigonometry asked students to work with others in pairs or small groups and one reserved on average 30 minutes of the class time for individual seat work. Technology (graphing calculator) was available in all the trigonometry classes; the calculator was used for graphing functions that had been drawn by hand, finding values of trigonometric functions, and performing complex computations.

The presentation of new material was guided by a pre-established sequence and organization of topics dictated by the syllabus or the textbook and included invariably the resolution of an example, which may or may not come from the textbook. Because the first 
author's interest resides in understanding how teachers manage to include students' participation in instruction and what are the qualities of the interaction, we focused on portions of sections in which instructors presented content using examples. There is substantial research on the role that examples play in mathematics teaching and learning, in particular their role in knowledge generation (Michener 1978; Watson and Mason 2005; Watson and Shipman 2008; Zaslavsky 2005; Zhu and Simon 1987).

Although other activity structures are also used in promoting student learning (e.g., seat work or work in small groups), we are interested here in the portions of instruction in which instructors illustrate concepts and procedures via examples that are solved at the board with participation of the students because this activity type can get at the contractual norms we are targeting, namely that teachers will elicit participation to corroborate that learning has happened. In our particular case, we focus on describing how the discussion of an example could play out in the situation of "finding values of trigonometric functions."

\subsubsection{Knowledge at Stake}

One quite central category of knowledge at stake in trigonometry consists of statements of relationships between trigonometric functions (e.g., $\sin ^{2} \theta+\cos ^{2} \theta=1$ ). One class of mathematical tasks in which students may demonstrate having knowledge of properties like those consists of determining the values of the trigonometric functions of specific (known and unknown) angles. For example they encounter tasks such as "determine the value of $\sin \theta, \tan \theta$,

and $\sec \theta$ given the values of $\cos \theta, \cot \theta$, and $\csc \theta "$. Thus, tasks of that kind create a context to teach and to learn the relationship between different trigonometric functions. Instructors thus need to officiate an exchange between students' completion of these kinds of tasks and the 
assertion that they have learned those relationships. We hypothesize that this instructional exchange between that kind of task and the object of study is framed by an instructional situation that we call "finding the values of trigonometric functions". This situation frames the exchange between two terms: on the one hand the claim by the teacher that students have had the opportunity to learn basic trigonometric identities and on the other hand the interactive work that teacher and students do over tasks of calculating the values of selected trigonometric functions. Because our interest is in probing contractual norms, any situation would serve the purpose of providing content. We selected finding values of trigonometric functions because it is a recurrent theme in trigonometry, and it is revisited several times with the purpose of illustrating different ways to find those values: by using ratios on a unit circle, by using the calculator, by using identities, by using the formulas for the sum or difference of two angles, etc.

\subsubsection{Anticipated Final Use}

Our objective in the design of the animations is to create representations of teaching that showcase the activity structure of working through an example on the board but where some of the contractual norms hypothesized might be breached. Our intention is to use those animations in conversations with trigonometry instructors; we expect that in listening to their reactions to the breaches of those norms we will learn about the rationality that keeps those norms in place. We turn now to the description of those norms.

\subsection{Identifying Key Norms of the Didactical Contract}

An important characteristic of the interaction in these classes is that they are teacher-led. The instructor is responsible for presenting the material and solving examples on the board. Students are responsible for doing homework, showing up for class, asking questions whenever they do 
not understand something, taking tests, and participating in class as demanded by the instructor. Students work under the following assumptions: that their teachers are there to help them gain competence with the material, that their teachers will press them to do challenging work, and that they themselves are capable of doing what it takes to be successful (Mesa 2010a). The instructors are very aware of the multiple demands that their students have on their time due to work and family responsibilities, and have learned to not take it personally when students stop coming to their class (Grubb and Associates 1999; Seidman 1985). Teachers are also aware of the "holes" that students have in their mathematical preparation that limit students' opportunities to grasp all the needed notions and the limitations in time that they have to ensure students' development of competence with the material.

When attending to excerpts in which exemplification occurs, we notice the following:

- Instructors rarely ask questions regarding the plausibility or correctness of a response or a final solution to a problem;

- Instructors engage the students by asking questions about how to apply known procedures rather than asking them to decide what procedure to apply;

- Instructors offer as examples problems that contain all the information needed to produce only one solution.

These three aspects are related to strategies for controlling the work while working on particular problems, and thus they play a significant role in shaping mathematical conceptions (Balacheff and Gaudin 2010). As it has been identified elsewhere, examples in textbooks do not make these elements visible either (Mesa 2010b; Mesa and John 2009; Suh, Mesa, Blake and Whittemore 2010). Such work is also absent in the corpus of taught lessons, and thus exploring 
the rationality for such absence is necessary. The three norms that we have identified are labeled, Justification, Control, and Set-up, and the three of them address various aspects of the control structure:

1. No one is responsible for justifying steps on an example or for explaining why an answer makes sense;

2. Students do not have control over what steps to follow when instructors solve examples on the board;

3. The instructor always gives sufficient information to solve the problems given as examples.

Those norms are contractual because they describe the division of labor over knowledge across many different objects of study. They are in particular instantiated in the situation of finding the values of trigonometric functions. An additional norm that cuts across these relates to students' participation. Students need to participate in order to show their engagement with the lesson, to show that they have learned or that they are learning. The three norms listed above specify how their participation can happen: in particular it indicates that students' participation is restricted to executing steps. Other conceivable forms of participation, such as proposing givens, justifying a step or an approach, or deciding what to do are out of bounds for their participation.

\subsection{Selecting or Creating a Scenario that Illustrates the Current Norms}

In selecting a scenario that could be used for breaching the norms, we attended to several features: length, content, amount of interaction, and location within the lesson. Main sources were the transcripts and field notes from observed lessons. We identified all transcripts that addressed "finding values of trigonometric functions" but avoided segments in which instructors 
presented these examples while reviewing homework or answers to tests because we wanted to have specific information from a given class about what had been done before that could justify the use of any given strategy. We avoided examples that were under 2 minutes, as these usually did not give enough material to alter the patterns of participation, and those that were over 5 minutes as these included more material than what would be needed for illustrating a particular norm. Amount of interaction and the types of questions that the instructors were asking were important also. We identified four possible scenarios and the one that we are discussing here, had the best entry points for breaching the norms in multiple ways.

We take a segment halfway through a two-hour long class taught by a full time instructor. The lesson is at the beginning of a unit called "Identities" (Chapter 4 in the textbook) and it is within a section called "Fundamental identities and their use." The unit comes after units on right triangle ratios (Chapter 1), trigonometric functions (Chapter 2), and graphing trigonometric functions (Chapter 3). Other sections in this chapter deal with verification of trigonometric identities, identities for sum, difference, co-functions, double and half angles, and product-sum and sum-product identities. Two more units, Inverse functions, equations and inequalities (Chapter 5), and Vectors (Chapter 6) would be covered after. The lesson was recorded in the $9^{\text {th }}$ week of a 15-weeks semester. The instructor had written basic trigonometric functions in terms of other functions (e.g., $\tan x=\frac{\sin x}{\cos x}$ ) and the Pythagorean identities (e.g., $\sin ^{2} x+\cos ^{2} x=1$ ) and intended to use them to solve problems that had been answered previously using the unit circle. We use as reference a four-minutes episode in which she introduces how these identities are used with an example. The instructor frames the example in terms of an application of ideas and concepts that students have seen before; she suggests that things should be familiar to the 
students and that identities will keep "things simple," emphasizing the familiarity of the possible actions. The example is the following:

If and use the fundamental identities to find the exact values of the remaining trigonometric functions of $x$. (Barnett et al. 2006, p. 220)

She begins by asking which other two trigonometric functions can be derived immediately ("what are the two we automatically get for free? ") which she answers herself by giving the values for cosecant and tangent, presumably by using the definitions she wrote on the board $(\sin x=1 / \csc x ; \cot x=1 / \tan x)$. She calls attention to the sign of the two given functions next, and uses the knowledge on the sign of the functions in the different quadrants to conclude that the sin of cosine must be positive ("let's say quadrants here. Sine is negative, so is tangent. What does that mean about cosine?"). In this exchange, however, a student answers the question incorrectly ("second") to which the teacher reacts by giving the right response and a justification (“One and four, right? Because cosines are $x$-values") and concluding that $x$ must be in quadrant four ('We're in quadrant four, aren't we? We're in quadrant four. Cosine is positive, sine is negative, so quadrant four."). She remarks that this is an important piece of information that might be necessary in solving these problems ("we always need quadrant information to do this kind of thing"). She moves to find the value of cosine - so far we have been concerned with its sign and the position of the angle - and uses a Pythagorean identity on the board, , to find it. After the computations she obtains two values, a positive and a negative for the cosine. In this process, however, she publicly states that she "rewrote" 1 in as , and that she used "common denominator" both references to manipulations that she might perceive as necessary to spell out for the students. The question 
about which value of cosine is chosen is by now known, but she seeks an explanation ("Cosine is positive three-fifths, why? Why did we choose that?'), which a student restates as 'it,' (presumably the angle) being in quadrant four, which the teacher corroborates ("quadrant four forced that choice"). She then obtains secant by inverting cosine, mentions once more that the angle is in quadrant four and concludes by counting the identities. She ends by reassuring the students that the process was not very difficult ("We're done, we got them all. That was okay, wasn't it?").

In this episode, the teacher is in charge of the solution process; she is determining what needs to be done and when and asking for students' input to fulfill the plan she has for the solution. That there is no room for departure is illustrated by how she answers her own questions when students do not propose an answer or when they respond incorrectly; incorrect responses are not addressed, but ignored. This also illustrates that she is the one responsible for asking questions. She uses information on the board, the focus of the lesson, but there is no reference to this in the solution. In addition, there is no time spent to discuss the justification for why each step in the process is justified, whether the answers make sense, or whether there could be other possible ways to find the solution to the problem. Finally, the problem leads to a unique set of trigonometric functions. Making assumptions or considering different cases, is not part of the work illustrated in trigonometry classes; as stated, the task is fully determined and solvable without ambiguity. The information provided is sufficient to solve the problem and there is in principle, no redundant or superfluous information. In the segment there are very few pauses that would allow students to reflect on particular steps or to think about questions the instructor poses which illustrates the role of the student as suppliers of correct information that feeds into the teachers' plans for solution. Thus this episode illustrates well that no one is responsible for 
justifying steps on an example or for explaining why an answer makes sense, that students do not have control over what steps to follow when instructors solve examples on the board, and that the instructor always gives sufficient information to solve the problems given as examples.

\subsection{Proposing Alternative Scenarios That Instantiate Breaches of the Norms}

We turn now to descriptions of scenarios that breach some of these norms. ${ }^{2}$ We have titled the altered scenarios to illustrate the focus of the norm to be breached, but in any given scenario there are more instances in which instructors might see a breach on other norms. Below we describe each scenario and give our explanation of why there is a breach and our hypothesis of how the instructors will react to it.

\subsubsection{Justification: “Why Does This Make Sense?”}

With this scenario we seek to breach the norm "No one (neither the teacher nor the students) is responsible for justifying steps on an example or for explaining why an answer makes sense." Our interest in this aspect comes from a conviction that justification and making sense of the work are important aspects of mathematical work, independently of how basic that content may appear, and thus with the breaches we seek to find out why justification is not more prominently emphasized in these classrooms.

An important feature of this task is the justification for why the cosine of the angle $x$ has to be positive. There are at least three possible alternatives for the justification. The first alternative, which would be the one we would anticipate instructors would prefer is to return to the chart in which the signs of the functions have been identified, to see that cosine is always

\footnotetext{
${ }^{2}$ Space considerations limit our use of the full transcripts. We render descriptions of the scenarios to convey an idea of their content.
} 
positive in quadrants 1 and 4. To elicit this explanation we have the teacher in the altered scenario draw a circle on the Cartesian plane. In here, the signs of the functions are determined by the position of the sides that determine the angle. The circle might implicitly bring definitions of the trigonometric functions as ratios of lengths of sides of a right triangle rather than the definitions that were extended to the real numbers in the previous chapter. The second alternative includes finding the values of $x$ for which sine $x$ is $-4 / 5$. To elicit this explanation we have a student finding the arcsin of $-4 / 5$, avowedly with the calculator. The third alternative is to draw the graphs of the trigonometric functions on the same Cartesian plane and use them to locate the known values for $\sin x$ and $\cot x$. Marking the possible angles on the number line might immediately illustrate the signs of all the trigonometric functions of an angle $x$ that satisfies both conditions, and force the positive sign for cosine.

We hypothesize that instructors would prefer the first alternative because it uses the content at stake. We believe that a scenario that includes finding arcsine with the calculator might be perceived as a very clever move from the student's part, which would illustrate that the student had prior knowledge about inverse trigonometric functions (because these have not yet been covered). While watching the animation they might indicate that this is an unlikely move for students to make. But, instructors would likely value if a student brings that information to the discussion and expect that the instructor could say "that is a good idea; at the same time one has to be careful, as the calculator is giving you one of many possible values of $x$ that satisfy the statement $\sin x=-4 / 5$." We hypothesize that a scenario using the graphs of the functions could also be seen as a clever move as it would connect the information from the previous chapter into the resolution of the problem. Instructors might appreciate the connection, but simultaneously worry that the example has not been solved using the content of the chapter. While 
acknowledging the qualities of these alternatives, instructors would likely prefer a solution that uses the knowledge at stake so that they could attest students have learned said content, therefore confirming that they had fulfilled their obligation in the contract.

In the original excerpt the instructor does not explicitly state why the angle must be in quadrant four, given the conditions of the problem. In the scenario just proposed, the instructor asks students to provide this justification. We hypothesize that usually neither teacher nor students are accountable to offer, or expected to require, a justification; and so the scenario proposed includes a breach of this norm. With this breach we direct attention to the importance to attend to how the definitions of the trigonometric functions enter into determining their sign and the connection with the magnitude of the angle they are functions of, beyond its location on the Cartesian plane. Adding a student using the calculator is another breach because it gives students a share of labor they don't normally have-access to the calculator in this situation, as the task does not call for obtaining the value of the angle and because there is an assumption that the calculator does not produce 'exact' values. In addition, we are creating another opportunity to investigate how instructors handle the justification for why it is mathematically incorrect to propose that the $\arcsin (-4 / 5)$ is (just) one angle in quadrant four, and bring to the fore the extension of the definitions of trigonometric functions to the real numbers. We hypothesize that instructors may use this opportunity to remind students that it is problematic to take the calculator results at face value.

The altered scenario also instantiates breaches of the contractual norms governing student participation, as we have several students proposing these alternatives. On the one hand, instructors might say that they like that students in the scenario participate without being prompted; they might attribute these interactions to personal characteristics of students (those 
students are confident, not shy), to students' perceptions about instructor's authority (the instructor and not their peers must provide the necessary correct information), or to the particular questions that the instructor asks. They might find a student's plea, "I'm so confused", and his request for 'starting over' as an illustration that students expect the instructor to give the final correct procedure. A variation of the scenario excluding the plea might give us evidence that instructors perceive students as holding them accountable for the correct knowledge, if instructors say, "I am surprised they don't say they are confused." Thus we anticipate that the instructors will qualify this scenario as unlikely, and potentially generating too much uncertainty among the students which, in their view, may not be regarded as desirable or appropriate.

\subsubsection{Control: "Which Step Should We Do Now?"}

A second scenario is aimed at probing the hypothesized norm that students have no control over the choice or order of steps in the procedure. In this scenario the instructor is completely removed from the interaction and the students solve the problem using prior knowledge returning to the circle definitions of the functions. We anticipate that relinquishing control will not be seen as a feasible alternative, for two reasons. First, students are perceived as expecting the instructor to be in control, showing how things are done, and with the responsibility of explaining the content; in principle students react negatively to what other students have to say, because they do not see their peers as having authority or knowledge to do that (Cox, 2009). Second, there is too much material to cover and a very efficient way to handle it in reasonable time is for the instructor to illustrate the process so students can reproduce it later (Grubb and Associates 1999). In this scenario, the students 'solve' the problem using relationships in the unit circle but the approach is of less value or import, because it does not use the content of the unit. The instructor will need to validate the solution given by the students or to reject it as inadequate for the 
expected use of the new content. Thus, if the teacher gives control of the solution to the students he or she risks losing control of the exchange value of the problem/solution. In either case, we hypothesize, the instructors would make sure that in addition to the proposed solution, the students would also see how the new content is used. This process might require an investment of time that might put instructors behind their schedule and jeopardize their chances of covering the material. At the same time instructors might see that this is a good opportunity to make connections to other topics in the curriculum, which they may see as useful for creating robust understanding of these notions; they might in such case imagine that this knowledge could pay off later on.

Instructors might appreciate having students propose or sort out alternatives because this is the kind of work that is required in more advanced mathematics. They might see why an instructor would like to teach that way, but say that trigonometry might be not the best place for doing this work. They might say that this course seeks to familiarize students with basic notions of trigonometry and develop their competence with fundamental procedures (e.g., as an instructor said in an interview "the course is about getting the procedures right and the skills up to snuff') and see the students' move as a response to their need of refreshing and rehearsing what they have learned and at the same time, unsure about how to use the new knowledge. Reasoning this way, the instructors would make a case for the need to showing the students how the work needs to be done, thus exposing this as a norm of the contract.

We anticipate that instructors will take students' bypassing of the new material as an opportunity to make connections between the old and the new ways of seeing the functions, saying something along the lines: "yes, that is a way to do this, and it is very good that you are using that information to solve the problem; but let me show you how we can arrive at the same 
solution with these new identities" or they can ask whether the students could use the identities to solve the problem. We anticipate the instructors suggesting that the instructor in the scenario remind the students to use the new identities as they do their homework problems so they can practice and learn them; they would reiterate that they are the same thing, and in fact that it is the same content.

\subsubsection{Set Up: "Why Do We Have Two Answers?"}

With the third scenario we breach the hypothesized norm that trigonometry instructors (and, their textbooks) always give sufficient information to solve the exercises. We hypothesize that adding redundant information (e.g., the quadrant in which the angle is located) only makes the problem 'easier' in the eyes of the instructor and eliminates the need for making that decision based on the signs of the two functional values given. We anticipate that breaching the norm by adding information may not be as interesting as doing so by reducing information. There are more opportunities for repair in the latter kind of breach.

Thus in this scenario we give a problem that has insufficient information to generate a single set of values for the trigonometric identities (by removing $\cot x=-3 / 4$ ). From our experience observing these classes, we know that this is an infrequent type of problem in class and in the textbook. Case analysis appears with problems involving absolute value and in some cases with problems involving quadratic polynomials. Multiple solutions appear later in the chapter when finding angles using inverse functions. In this scenario, we have the instructor avoiding calling attention to the assumption about the quadrant in which the angle is, in order to make the transcript look more fluid and more aligned with the idea of fulfilling illustrative purposes. We have added a student asking for a justification ("how do you know that the angle is in quadrant 
four") and also kept the instructor's response direct ("I don't") and with an invitation for suggestions ("what should we do?"). We also have the students solving the other possible case to again remove the instructor from the interaction. As a last line we have a student ask "why do we have two answers? Which answer is correct," a question that is meant to require the instructor to be explicit about why two cases are considered and for observers to take a stance about the problem itself: Is it appropriate to ask these types of questions at the beginning of the unit? Can students expect this sort of work in examinations?

We anticipate instructors will enjoy the scenario, as it would be an unusual case in which students would need to make assumptions in order to be able to break through the impasse of having incomplete information. They would see it as a demanding task that would require paying attention to the conditions of the problem and an opportunity for students to be creative. At the same time, we anticipate that they will find the set up prone to creating confusion among some students. We hypothesize that the instructors might see this task as viable for the more confident students in the class or for those who might have experienced tasks with multiple solutions recently in their high school preparation. We anticipate the instructors might see this as a bold move on the part of the instructor that would target important knowledge in mathematics: how to deal with uncertainty, and would acknowledge this as an important goal to have. Instructors might suggest that such set up is more viable in calculus, with content in which the analysis of cases would be more natural (absolute value, initial value problems). We anticipate that instructors would keep in mind that these are trigonometry students, and might prefer to add the missing information in order to find a single set of functions; this repair to the task would confirm our hypothesized norm. 
Alternatively, instructors might expect the teacher in the scenario to be more explicit about the need for having to consider two alternatives, rather than going over them without calling students' attention about what she is about to do, that is, to be more explicit about her intentions in the process, rather than leaving students to figure out what is going on to their own devices. A student question such as "which is the answer?" would be used to legitimize students' discomfort with having more than one set of plausible responses or the teacher's lack of sensibility to the need to scaffold the process. These moves target the hypothesized contractual norm that examples solved on the board should reduce uncertainty and be clearly delineated, so that students can reproduce the work on their own.

We anticipate that instructors might consider giving tasks such as the one in the proposed scenario towards the end of the semester, during review, or when there is extra time for exploration. Instructors might like that the task allows for calling attention to conditions that would lead to single solutions; they might also suggest that instead of removing the value of cotangent, students be given the quadrant information. By giving the value of sin and the quadrant information the problem has a unique solution, but the process of determining the missing functions with the identities might be more complex. Because of the constraints in the curriculum, the emphasis on gaining proficiency with techniques, and the students' attitudes towards problem solving, instructors might say that having a known structure and a straightforward problem would be better suited to rehearse the technical knowledge, and leave the more abstract process for a time in which students feel more confident. 


\subsection{Anticipating Justifications or Rejections for the Breaches}

Instructors might see the discipline of mathematics as a source of justification for the breaches proposed here because they target reasoning skills that are fundamental for mathematics. Justifying why a particular step makes sense, testing cases, and making assumptions, are all skills that are important as one develops mathematical proficiency. Seeing the discipline in this way might make the teachers justify all these breaches as instrumental for fulfilling these larger mathematical objectives. Perceptions of the role of the trigonometry course in the college curriculum as providing skills and technical knowledge for more advanced subjects (such as calculus or differential equations) might however justify not spending course time on extraneous activity — we deem this a disposition to respond to the institutional obligation (in this case as regards to the curriculum sequence and available time).

Instructors might also justify the breaches on grounds that they enable meeting their obligation to students as individuals for example by acknowledging that students can bring prior knowledge from earlier experiences to bear on the solution in spite of the fact that such knowledge would be covered later in the term (e.g., students who took trigonometry in high school might have the idea of using arcsine). They might also accept the breach for participation on account that they enable meeting their obligation to the class as a group, for example by indicating that students need to be able to tell others what they think. They might praise the students for exhibiting these traits, as those are desirable for being successful in mathematics.

Instructors might justify breaches on interpersonal grounds by indicating that instructors need to let these students speak during class as in these scenarios so the students learn to listen to each other's ideas, so they can discern what is correct from what is wrong and be able to communicate this to the rest of the class politely. 
Animations designed in this way and shown to experienced teachers have been successful in having teachers look past the appearances of the characters and focus on the practices they enact (Herbst and Chazan, 2006). While initial reactions may include chuckles or disbelief the scenarios contain sufficient similarities with the practices that teachers do that they are usually willing to bring their tacit knowledge of instruction to respond to the probes. Instructors observing the scenarios proposed here would either understand why these moves might be desirable to have, reject the situation by indicating that such interaction would not be what teachers would do when finding the values of trigonometric functions, or attempt to repair it by suggesting moves they would have done to make sure the work would be useable as an example for facilitating students' work on their homework.

We expect to be able to uncover the resources instructors have at their disposal for making decisions regarding how to manage similar scenarios. They would either align with or distance from the teacher in the scenario and in that process they would make explicit what they have that the animated teacher does not, or otherwise be curious about what the teacher did to get her students behaving in that way and whether it pays off at the end, that is, whether students are successful in the courses they take.

Differently from K-12 teachers, the community colleges instructors might feel less pressure to attempt to engage students in classroom discussion, in spite of the prominence of such expectation in reform documents. The presence of adult students with heavy time constraints would appear as enough warrant to dispute the possibility that students can (or want to) engage in a mode of interaction that requires a radical break with their expectations about what college mathematics classrooms should look like. Research in other areas (e.g., Cox 2009) would give credence to the observation that community colleges students engage in learning practices that 
are at odds with the intention of creating autonomous learners (Wheeler and Montgomery 2009)

and that it is difficult and unrewarding for instructors to alter those attitudes. Likewise, community colleges instructors are likely to indicate their lack of conviction that attempts to change the norms of classroom interaction would give the students the needed tools for succeeding in the following courses: They see their primary goal as one of helping students move along (and simultaneously to determine who is ready to do so and who must wait) in terms of what students know about the material, how competent they are, and how they can demonstrate the mastery of the content. With the content perceived as mostly technical, they would sanction the repetition and modeling of known procedures as fundamental for students to gain familiarity with the material, which would eventually demonstrate they have mastered it.

\section{Conclusion}

The foregoing shows how the process of modeling an instructional situation and prototyping breached instances of it can be used to specify representations of teaching with which to study the practical rationality of community college mathematics instructors. Grounded in the teaching of trigonometry we identified the situation of "finding the values of trigonometric functions" and three contractual norms that apply in this situation. For each of those norms we indicated what a breach of that norm would consist of; we then modeled that breach by altering, in deliberate ways, a classroom transcript which is part of our data corpus. Each of the scenarios proposed embodies a designed breach of what is customary and how those breaches might lead to a desirable practice - that of increasing classroom discourse. The scripts so produced are then turned into voice tracks and each of the voice tracks overlaid with an animation of cartoon characters acting the scenarios. The animations can then be used to broker conversations with 
community college instructors where we expect to find confirmation or refutation of the hypothesized reactions stated in here.

“Design experiments are conjecture-driven tests" (Cobb, et al 2003, p. 10). This initial design of a research tool that probes community college instructors' rationality in teaching trigonometry with examples will give us opportunities to test our conjectures about the norms of the didactical contract with groups of instructors. The data that we will collect would then allow us to formulate more specific conjectures that will then be probed further. If a particular conjecture is refuted, we will be able to formulate new ones to be tested, with the cycle starting over again.

\section{Acknowledgements:}

The research reported in this article is supported by the National Science Foundation grants DRL-0745474 to the first author and ESI-0353285 to the second author. Opinions expressed here are the sole responsibility of the authors and do not reflect the views of the Foundation.

\section{References}

Bailey, T. R., \& Morest, V. S. (2006). Defending the community college equity agenda. Baltimore: Johns Hopkins University Press.

Balacheff, N., \& Gaudin, N. (2010). Modeling students' conceptions: The case of function. Research in Collegiate Mathematics Education, 16, 183-211.

Barnett, R. A., Ziegler, M. R., \& Byleen, K. E. (2006). Analytic trigonometry with applications (9th ed.). Hoboken, NJ: Wiley.

Blair, R. (Ed.). (2006). Beyond crossroads: Implementing mathematics standards in the first two years of college. Memphis, TN: American Mathematical Association of Two Year Colleges. 
Brousseau, G., \& Otte, M. (1991). The fragility of knowledge. In A. Bishop, S. Mellin-Olsen \& J. van Dormolen (Eds.), Mathematical knowledge: Its growth through teaching (pp. 13-36). Dordrecth, The Netherlands: Kluwer.

Cobb, P. (2000). Conducting teaching experiments in collaboration with teachers. In A. Kelly \& R. Lesh (Eds.), Handbook of research design in mathematics and science education (pp. 307-334). Mahwah, NJ: Erlbaum.

Cobb, P., Confrey, J., diSessa, A., Lehrer, R., \& Schauble, L. (2003). Design experiments in educational research. Educational Researcher, 32(1), 9-13.

Cox, R. D. (2009). The college fear factor: How students and professors misunderstand one another. Boston, MA: Harvard University Press.

Garfinkel, H., \& Sacks, H. (1970). On formal structures of practical action. In J. McKinney \& E. Tiryakian (Eds.), Theoretical sociology: perspectives and development. New York: Appleton-Century-Crofts.

Grubb, N. W., \& Associates. (1999). Honored but invisible: An inside look at teaching in community colleges. New York: Routledge.

Herbst, P. (2006). Engaging students in proving: A double bind on the teacher. Journal for Research in Mathematics Education, 33, 176-203.

Herbst, P. (2010, April). What practical rationality is. Paper presented at the Research Pre-session of the Annual Meeting of the NCTM. San Diego, CA.

Herbst, P., \& Balacheff, N. (2009). Proving and knowing in public: What counts as proof in a classroom. In D. Stylianou, M. Blanton \& E. J. Knuth (Eds.), Teaching and learning proofs across the grades (pp. 40-64). New York: Routledgle.

Herbst, P. \& Chazan, D. (2003a). Exploring the practical rationality of mathematics teaching through conversations about videotaped episodes: The case of engaging students in proving. For the Learning of Mathematics, 23(1), 2-14.

Herbst, P. \& Chazan, D. (2003b). ThEMaT: Thought Experiments in Mathematics Teaching. Proposal to the National Science Foundation, Education and Human Resources Directorate, Division of Elementary, Secondary, and Informal Education, Teachers’ Professional Continuum Program. University of Michigan, Ann Arbor. 
Herbst, P., \& Chazan, D. (2006). Producing a viable story of geometry instruction: What kind of representation calls forth teachers' practical rationality? Paper presented at the 28th annual meeting of the North American Chapter of the International Group of the Psychology of Mathematics Education, Mérida, Mexico.

Herbst, P., Chen, C., Weiss, M., \& González, G. (2009). "Doing proofs" in geometry classrooms. In D. Stylianou, M. Blanton \& E. J. Knuth (Eds.), Teaching and learning of proof across the grades (pp. 250-268). New York: Routledge.

Herbst, P., \& Miyakawa, T. (2008). When, how, and why prove theorems: A methdology to study the perspective of geometry teachers. ZDM The International Journal on Mathematics Education, 30, 469-486.

Herbst, P., Nachlieli, T., \& Chazan, D. (in press). Studying the practical rationality of mathematics teaching: What goes into "installing" a theorem in geometry? Cognition and Instruction.

Keim, M. C., \& Biletzky, P. E. (1999). Teaching methods used by part-time community college faculty. Community College Journal of Research and Practice, 23(8), 727-737.

Kelly, A. (2004). Design research in education: Yes, but is it methodological? Journal of the Learning Sciences, 13, 115-128.

Lutzer, D. J., Maxwell, J. W., \& Rodi, S. B. (2002). Statistical abstract of undergraduate programs in the mathematical sciences in the United States: Fall 2000 CBMS Survey. Washington, DC: American Mathematical Society.

Lutzer, D. J., Rodi, S. B., Kirkman, E. E., \& Maxwell, J. W. (2007). Statistical abstract of undergraduate programs in the mathematical sciences in the United States: Fall 2005 CBMS Survey. Washington, DC: American Mathematical Society.

Mesa, V. (2004). Characterizing practices associated with functions in middle school textbooks: An empirical approach. Educational Studies in Mathematics, 56, 255 - 286.

Mesa, V. (accepted). Similarities and differences in classroom interaction between remedial and pre-STEM college mathematics classrooms in a community college. Journal of Excellence in College Teaching. 
Mesa, V. (2010a). Achievement goal orientation of community college mathematics students and the misalignment of instructors' perceptions (Manuscript under review). Ann Arbor, MI: University of Michigan.

Mesa, V. (2010b). Strategies for controlling the work in mathematics textbooks for introductory calculus. Research in Collegiate Mathematics Education, 16, 235-265.

Mesa, V., \& John, G. (2009). Textbook analisys (Unpublished manuscript). Ann Arbor: University of Michigan.

Michener, E. R. (1978). Understanding understanding mathematics. Cambridge, MA: Massachusetts Institute of Technology.

Midgley, C., Maehr, M. L., Hruda, L. Z., Anderman, E., \& Others. (2000). Manual for the Patterns of Adaptive Learning Scales. Ann Arbor, MI: University of Michigan.

National Council of Teachers of Mathematics [NCTM]. (2000). Principles and standards for school mathematics. Reston, VA: Author.

Schuetz, P. (2002). Instructional practices of part-time and full-time faculty. New Directions for Community Colleges, 118, 39-46.

Seidman, E. (1985). In the words of the faculty: Perspectives on improving teaching and educational quality in community colleges. San Francisco, CA: Jossey-Bass.

Suh, H., Mesa, V., Blake, T., \& Whittemore, T. (October, 2010). An analysis of examples in college algebra textbooks: Opportunities for student learning. Paper presented at the Annual Meeting of the Michigan Chapter of the American Mathematical Association of Two-Year Colleges, Muskegon, MI.

Watson, A., \& Mason, J. (2005). Mathematics as a constructive activity. Mahwah, NJ: Erlbaum.

Watson, A., \& Shipman, S. (2008). Using learner generated examples to introduce new concepts. Educational Studies in Mathematics, 69(2), 97-109.

Wheeler, D. L., \& Montgomery, D. (2009). Community college students' views on learning mathematics in terms of their epistemological beliefs: A Q method study. Educational Studies in Mathematics, 72, 289-306.

Zaslavski, O. (2005). Seizing the opportunity to create uncertainty in learning mathematics. Educational Studies in Mathematics, 60, 297-321. 
Zhu, X. \& Simon, H. (1987). Learning mathematics from examples and by doing. Cognition and Instruction, 44, 137-166. 